\title{
Análise financeira e de sensibilidade de sistemas de produção de leite em pastagem $^{1}$
}

\author{
Afonso Aurélio de Carvalho Peres ${ }^{2}$, Hernán Maldonado Vásquez ${ }^{3}$, Paulo Marcelo de Souza ${ }^{3}$, \\ José Fernando Coelho da Silva ${ }^{3}$, Omar Vieira Villela $^{2}$, Fernando Cesar dos Santos ${ }^{2}$ \\ 1 Pesquisa financiada com recursos da APTA e FAPERJ. \\ 2 Pólo APTA Vale do Paraíba, Agência Paulista de Tecnologia dos Agronegócios (APTA), Caixa Postal 07, Av. Prof. Manoel César Ribeiro, 320, \\ Santa Cecília, CEP: 12.400-970, Pindamonhangaba, SP. \\ ${ }^{3}$ Centro de Ciências e Tecnologias Agropecuárias, Universidade Estadual do Norte Fluminense (UENF), Av. Alberto Lamego, nº. 2000, Parque \\ Califórnia, CEP: 28.013-602, Campos dos Goytacazes, RJ.
}

RESUMO - Realizou-se neste estudo uma análise econômica de sistemas de produção para vacas em lactação manejadas em pastagem de capim-mombaça recebendo diferentes fontes de suplementação volumosa durante a época seca do ano. As suplementações fornecidas foram: pastagem de aveia-preta, cana-forrageira com ureia e silagem de sorgo. Utilizaram-se como indicadores econômicos o valor presente líquido (VPL) e a taxa interna de retorno (TIR). Para cada sistema de produção estudado, foi construído um fluxo de caixa, com sua particularidade e índices de desempenhos produtivo e reprodutivo, obtidos experimentalmente. Os fluxos de caixa foram construídos mensalmente para um período de 12 anos e os VPL dos sistemas foram calculados aplicando-se taxas de desconto de 6, 8, 10 e 12\% ao ano. Com uma taxa anual de desconto de $8 \%$, todos os sistemas de produção foram viáveis financeiramente. O capital investido apresentou TIR anuais de 11,91\% para pastagem de aveia-preta, 9,43\% para cana-forrageira e ureia e 8,46\% para silagem de sorgo. O item de maior impacto nos resultados econômicos dos sistemas, de acordo com a análise de sensibilidade, foi o preço de venda do leite produzido.

Palavras-chave: análise de sensibilidade, bovino de leite, suplementação volumosa, taxa interna de retorno, valor presente líquido

\section{Financial and sensitivity analysis of milk production systems under pasture}

\begin{abstract}
An economical analysis of milk production systems was made with lactating cows on Mombaça grass pasture receiving different sources of roughage supplementation during the dry season. The supplementations were: black oat pasture, forage sugarcane with urea and sorghum silage. The economical indicators used were: net present value (NPV) and internal rates of return (IRR). For each production system studied one cash flow was used with their particularities and productive and reproductive performances index, obtained experimentally. The cash flows were built monthly, for a 12 years period and the NPV of the systems were calculated applying discount rates of 6, 8, 10 and 12\% a year. At an annual discount rate of $8 \%$ all the production systems were financially viable. The invested capital showed annual IRR of $11.91 \%$ for black oat pasture, $9.43 \%$ for forage sugarcane and $8.46 \%$ for sorghum silage. The sensitivity analysis showed that the milk selling price had greatest economic impact on the profitability of the systems.
\end{abstract}

Key Words: dairy cattle, internal rates of return, net present value, roughage supplementation, sensitivity analysis

\section{Introdução}

No Brasil, a cadeia agroindustrial do leite passou por mudanças estruturais, resultantes da desregulamentação do mercado, do acesso aos mercados externos e do processo de estabilização da economia. Essas mudanças surgiram a partir de 1990, quando o mercado se tornou mais competitivo (Jank et al., 1999). Mais recentemente, houve a implantação da Instrução Normativa N.51 de 2002, que trata do aperfeiçoamento e de modernização da legislação sanitária federal sobre a produção de leite (MAPA, 2006).

Dados publicados por Krug (2000) refletem a má distribuição mundial do leite e elucida o potencial que a pecuária tem a explorar. Do leite produzido no mundo, $30 \%$ se encontram nos países em desenvolvimento, que abrigam $78 \%$ da população mundial. Por outro lado, 22\% da população dos países desenvolvidos têm à disposição a comercialização de 70\% do leite produzido. A má distribuição 
mundial gera um déficit na disponibilidade de leite per capita.

Diante desse quadro, a avaliação técnica e econômica de sistemas de produção que utilizam indicadores econômicos de rentabilidade pode proporcionar aos pecuaristas informações que indiquem o aumento da produção dos animais e da produtividade por área, com redução dos custos de produção e aumento da rentabilidade.

Os indicadores econômicos de rentabilidade utilizados em uma análise financeira são: o valor presente líquido (VPL) e a taxa interna de retorno (TIR). O valor presente líquido é considerado um critério de avaliação mais rigoroso e isento de falhas técnicas (Noronha, 1987) - a atividade é viável se apresentar um VPL positivo-, enquanto a taxa interna de retorno (TIR), definida por Contador (1988), é a taxa de desconto que iguala o valor presente dos benefícios ao valor presente dos custos de um sistema de produção, ou seja, iguala a zero. Um sistema é viável quando sua TIR é igual ou maior que o custo de oportunidade do capital.

Para identificar os itens que podem afetar os resultados econômicos de um sistema e influenciar na viabilidade financeira da atividade, utiliza-se a análise de sensibilidade (Buarque, 1991). Com a identificação dos itens mais importantes, o pecuarista pode evitar que erros futuros proporcionem grandes perdas econômicas.

Objetivou-se com este trabalho verificar a viabilidade econômica de sistemas de produção de leite, determinando-se os resultados do VPL e da TIR e realizar a análise de sensibilidade para identificar os itens de maior impacto econômico nos sistemas.

\section{Material e Métodos}

A análise financeira foi realizada com base nos levantamentos e nos dados obtidos em diferentes sistemas de produção de leite instalados no Pólo APTA Vale do Paraíba da Agência Paulista de Tecnologia dos Agronegócios (APTA), em Pindamonhangaba, São Paulo, durante o período de outubro de 2003 a setembro de 2005.

Foram avaliados três sistemas de produção utilizando-se vacas leiteiras do biotipo Mantiqueira manejadas em pastagem de capim-mombaça (Panicum maximum, cv. Mombaça) sob pastejo rotacionado. Durante a estação chuvosa (outubro-março), diariamente, os animais tinham como única fonte de alimentação volumosa a pastagem de capim-mombaça e recebiam no cocho, no momento da ordenha, $0,5 \mathrm{~kg}$ de concentrado, totalizando $1,0 \mathrm{~kg} / \mathrm{dia}$. $\mathrm{Na}$ estação seca (abril-agosto), a fonte de volumoso proveniente da pastagem de capim-mombaça era consumida no período noturno, entre as ordenhas da tarde e da manhã do dia seguinte. $\mathrm{O}$ fornecimento de concentrado foi o mesmo realizado durante a estação chuvosa. No período diurno, entre as ordenhas da manhã e da tarde, forneceram-se diferentes fontes de suplementação alimentar com volumosos. Cada sistema de produção instalado diferenciou-se pela fonte de suplementação volumosa fornecida, durante a estação seca: pastagem de aveiapreta, cv. Embrapa 29, diariamente, pelo método de pastejo em faixa; cana-forrageira, cv. IAC 86-2480, picada e fornecida diariamente no cocho, misturada com ureia, na quantidade de 50 g/animal/dia; e silagem de sorgo, cv. Volumax, fornecida no cocho diariamente. Em todos os sistemas de produção avaliados, forneceu-se suplementação mineral no cocho, à vontade. Os animais tinham acesso livre aos bebedouros e áreas de sombra.

O levantamento das informações para compor cada fluxo de caixa, caracterizando os diferentes sistemas de produção avaliados, foi realizado desde a implantação dos sistemas no primeiro ano até sua utilização para obtenção dos índices zootécnicos (desempenhos produtivo e reprodutivo das vacas leiteiras), no segundo ano, compreendendo as estações de chuva e seca. Foram considerados todos os custos envolvidos na implantação e manutenção de cada sistema, bem como as receitas advindas da venda da produção de leite e subprodutos. A partir daí, projetou-se um fluxo de caixa mensal com duração de 12 anos, considerando a vida útil das cercas utilizadas, desconsiderando sua depreciação, uma vez que esta projeção permite avaliar a longo prazo cada sistema de produção.

Utilizando-se planilhas do MS-Excel, foram computadas todas as quantidades gastas mensalmente com cada item do sistema de produção. Para os diversos itens levantados, foram consideradas diferentes categorias, dispostas em dois grandes grupos, entradas e saídas (Tabela 1).

Considerou-se ainda a vida útil das máquinas e dos equipamentos, as benfeitorias e instalações e determinou-se a depreciação desses bens, que posteriormente foi inserida no fluxo de caixa.

Os preços dos itens foram obtidos a partir de levantamento realizado em lojas agropecuárias, cooperativas, fornecedores, profissionais autônomos, representantes comerciais e vendedores durante o período de outubro de 2003 a setembro de 2005. Posteriormente, os valores foram corrigidos monetariamente pelo índice geral de preços disponibilidade interna (IGP-DI) da Fundação Getúlio Vargas (FGV, 2006). Adotou-se como base o índice 100 para o mês de setembro de 2005 e, a partir desse índice, os preços pesquisados foram deflacionados mensalmente durante os dois anos. Em seguida, determinaram-se o preço mínimo, 
médio e máximo para cada item de cada sistema de produção objetivando a realização de análise financeira.

Com a construção de cada planilha, foi possível obter o subtotal das receitas e das despesas em cada sistema no período de 12 anos e, a partir daí, determinar o fluxo de caixa mensal. Sobre o fluxo de caixa foram aplicadas diferentes taxas de desconto utilizando-se taxas de 6, 8, 10 e $12 \%$ ao ano, que correspondem a 0,$49 ; 0,64 ; 0,80$ e $0,95 \%$ ao mês, respectivamente.

Inicialmente, cada sistema de produção foi planejado para alocar um total de 60 vacas leiteiras, separadas em dois lotes de produção, 36 vacas em lactação na estação chuvosa e 24 vacas em lactação na estação seca, no primeiro ano. A composição dos anos subsequentes foi realizada, a partir dos desempenhos produtivos e reprodutivos apresentados, considerando ao longo do tempo o descarte de vacas e a aquisição de novas matrizes. As vacas que não se encontravam em lactação, ou seja, as vacas secas, eram levadas para pastos adjacentes, computando-se nas despesas a área em que permaneciam como aluguel de pastos.

A produtividade média de leite durante a lactação (305 dias) para animais com parição na estação chuvosa foi de 9,3 kg/vaca/dia, enquanto, para as vacas que tiveram a parição na estação seca, a produtividade média considerada foi de 10,3; 7,9 e 8,4 kg/vaca/dia para os sistemas que forneceram suplementação volumosa com aveia-preta, cana-forrageira e silagem de sorgo, respectivamente.

Adotaram-se à taxa de prenhez e o intervalo de partos observados nas vacas, após a aplicação da biotecnologia da reprodução, com a sincronização da ovulação e a utilização da inseminação artificial em tempo fixo (IATF). Na estação chuvosa, a taxa de prenhez das vacas sincronizadas foi de $60 \%$ e destas, $78 \%$ apresentaram intervalo de partos entre 11 e 14 meses e o restante, $22 \%$ acima de 14 meses. Para a estação seca, a taxa de prenhez considerada foi de $70 \%$. Das vacas prenhes, $60 \%$ apresentaram intervalo de parto entre 12 e 15 meses e o restante $40 \%$ acima de 15 meses.

A partir dessas considerações, utilizaram-se para efeito de estudo da análise financeira dois indicadores econômicos: o valor presente líquido (VPL) e a taxa interna de retorno (TIR).

O valor presente líquido corresponde à soma algébrica dos valores do fluxo de caixa, atualizados à taxa ou às taxas de desconto do período. Segundo esse indicador, a atividade é viável se apresentar VPL positivo.

A expressão para cálculo do VPL é a seguinte:

$$
V P L=\sum_{t=0}^{n} V F /(1+r)^{t}
$$

VPL = valor presente líquido; $\mathrm{VF}$ = valor do fluxo líquido (diferença entre entradas e saídas); $\mathrm{n}$ = número de fluxos; $\mathrm{r}=$ taxa de desconto; $\mathrm{t}=$ período de análise $(\mathrm{i}=1,2,3 \ldots)$.

Tabela 1 - Relação dos itens que compõem os sistemas de produção separados em dois grandes grupos

\begin{tabular}{|c|c|}
\hline Categoria & Descrição \\
\hline & Entrada (Receita) \\
\hline \multirow{4}{*}{$\begin{array}{l}\text { Leite } \\
\text { Animal } \\
\text { Valor residual }\end{array}$} & Venda do leite produzido, pagamento por cota e extracota e bonificação por qualidade \\
\hline & Venda de bezerras, bezerros, vacas de descarte, reprodutores, animais de trabalho e esterco de curral \\
\hline & Terras, máquinas, equipamentos, benfeitorias e instalações \\
\hline & Saída (Despesa) \\
\hline Área & Terras para pastagem, culturas e aluguel de pastos \\
\hline Benfeitoria & Construção de currais, salas de ordenha e de leite, máquinas, escritório, banheiro, entre outros \\
\hline Máquina & Carroça, carreta e microtrator, entre outros \\
\hline Equipamento & Ordenhadeira, tanque de leite, bombas de vácuo e de leite, picadeira, cochos para sal, bebedouros, arreios, entre outr \\
\hline Ferramenta & Pistola de vacinação, pá, enxada, rodo, brincador, tatuador, mangueira, cordas, entre outros \\
\hline Animal & Matrizes, reprodutor, animais de trabalho \\
\hline Pastagem & Corretivos, fertilizantes, sementes, análise de solo, operações mecanizadas \\
\hline Cerca & Eletrificador, arames liso e farpado, pregos, isoladores, moirões, porteiras, entre outros \\
\hline Alimentação & Fontes energéticas e proteicas, sal branco, sal mineral, ureia, ração granulada \\
\hline Reprodução & $\begin{array}{l}\text { Pipetas, bainhas, nitrogênio líquido, medicamentos para lavagem uterina, hormônios, dispositivo intravaginal para } \\
\text { sincronização da ovulação, sêmen, entre outros }\end{array}$ \\
\hline Sanidade & $\begin{array}{l}\text { Algodão, seringas, agulhas, vacinas, exames, carrapaticidas, antibiótico, antiinflamatório, antitérmico, antitóxico, } \\
\text { antimastítico, bernicidas, complexo vitamínico e mineral, ferraduras, cravos, entre outros }\end{array}$ \\
\hline Ordenhadeira & $\begin{array}{l}\text { Óleo para bomba, detergente alcalino e ácido, desinfetantes, material de limpeza, avental, camisa de filtro, papel toalha } \\
\text { resistência, peças de reposição, mangueiras de leite, tubos de pulsação, entre outros }\end{array}$ \\
\hline Mão-de-obra & Contratada, temporária, técnica, consultoria e encargos trabalhistas \\
\hline Combustível & Óleo diesel, óleo lubrificante, graxa, luz e água \\
\hline Imposto, taxa & ITR, IPVA, Funrural, associações, sindicatos, frete e carretos \\
\hline Outros itens & Reparos e manutenção em máquinas, equipamentos, benfeitorias e instalações \\
\hline
\end{tabular}


No cálculo do VPL, aplicaram-se as taxas de desconto sobre o fluxo líquido mensal de cada sistema de produção de leite instalado, determinando-se então quatro VPL.

A taxa interna de retorno, no entanto, é igual ao valor presente dos benefícios de um sistema ao valor presente de seus custos, ou seja, um sistema de produção é viável quando sua TIR é igual ou maior que o custo de oportunidade dos recursos utilizados para sua implantação e manutenção.

Para a TIR, segundo os critérios de aceitação, quanto maior o resultado obtido no sistema avaliado, maior sua atratividade. Assim, a TIR é o valor de r que iguala a zero a expressão:

$$
V P L=V F_{0}+\frac{V F_{1}}{(1+r)^{1}}+\frac{V F_{2}}{(1+r)^{2}}+\frac{V F_{3}}{(1+r)^{3}}+\cdots+\frac{V F_{n}}{(1+r)^{n}}
$$

$\mathrm{VF}=$ fluxos de caixa líquido $(0,1,2,3, \ldots, \mathrm{n})$; e r = taxa de desconto.

Determinou-se TIR para cada sistema de produção de leite, anualmente.

A análise de sensibilidade identifica o item ou os itens que podem exercer impacto nos resultados econômicos do sistema de produção e influenciar na rentabilidade da atividade. Por meio dessa análise, é possível determinar em que medida um erro ou modificação de uma das variáveis incide nos resultados do sistema (Buarque, 1991). Melo et al. (1999) descreveram a análise de sensibilidade como importante para se conhecer as variáveis (itens) que têm maior peso na determinação dos resultados do sistema, influenciando na mudança dos indicadores de rentabilidade. Essa análise permite ao pecuarista conhecer que erros futuros proporcionarão grandes perdas econômicas.

Para a realização da análise, os itens que compõem os fluxos de caixa de cada sistema foram estudados individualmente. Posteriormente, foi utilizada a taxa de desconto mais apropriada entre as utilizadas para determinação dos indicadores econômicos. Neste trabalho, para realização da análise de sensibilidade, adotou-se a taxa de desconto de $6 \%$ ao ano considerando uma variação de $10 \%$ sempre no sentido desfavorável para os resultados de cada sistema, ou seja, nos preços de cada item que compõem o fluxo de caixa. A partir daí, foi possível observar qual item teve maior efeito sobre o indicador de resultado econômico de cada sistema avaliado, isto é, o VPL. Em seguida, foram identificados os dez principais itens que compõem cada sistema de produção e que apresentaram os maiores valores econômicos de sensibilidade.

\section{Resultados e Discussão}

Todos os sistemas de produção avaliados foram viáveis economicamente quando submetidos à taxa de desconto de 8\% ao ano (Tabela 2). O sistema que utiliza suplementação volumosa com pastagem de aveia-preta apresentou VPL positivo à taxa de desconto de $10 \%$ ao ano, ao passo que os demais sistemas (cana-forrageira com ureia e silagem de sorgo) não foram viáveis economicamente quando submetidos a essa taxa de desconto. Esta situação torna o sistema mais atrativo para investimento, pois, quando submetido a maior taxa de desconto (10\% a.a.) apresentou VPL positivo, sinalizando melhor rentabilidade para a atividade.

A relação entre o VPL e o custo de oportunidade do capital dos sistemas de produção mostra que, quanto maior a taxa de desconto aplicada, menos atrativo se torna o sistema. Ao comparar a taxa de desconto com outra aplicação financeira disponível no mercado e de baixo risco, como a caderneta de poupança, pode-se considerar que os sistemas de produção avaliados são viáveis, pois, no mesmo período do estudo, a caderneta de poupança apresentou rentabilidade de $6 \%$ ao ano.

O maior VPL obtido para o sistema que utiliza pastagem de aveia-preta como suplementação volumosa evidencia a adoção desse VPL para investimento. Além desse indicador econômico, o pecuarista deve avaliar os itens que compõem o sistema e se esse sistema se enquadra nas características e peculiaridades de sua propriedade, bem como sua capacidade de gerenciamento e exploração. Outro fator que deve ser considerado é a disponibilidade de recursos financeiros, seja para a implantação, seja para a adequação do sistema de produção explorado atualmente.

O sistema de produção que utiliza suplementação volumosa com cana-forrageira durante a estação seca apresentou VPL positivo à taxa de desconto de $8 \%$ ao ano,

Tabela 2 - Valor presente líquido (em R\$) dos sistemas de produção considerando diversas taxas de desconto ao ano

\begin{tabular}{|c|c|c|c|c|}
\hline \multirow[b]{2}{*}{ Sistema de produção } & \multicolumn{4}{|c|}{ Taxas de desconto } \\
\hline & $6 \%$ & $8 \%$ & $10 \%$ & $12 \%$ \\
\hline Pastagem de aveia-preta & $132.509,84$ & $79.387,12$ & $35.323,80$ & - $1.458,11$ \\
\hline Cana-forrageira com ureia & $63.446,07$ & $23.938,52$ & - 8.791,35 & $-36.074,49$ \\
\hline Silagem de sorgo & $48.439,97$ & $8.179,75$ & $-25.098,63$ & - $52.776,42$ \\
\hline
\end{tabular}


taxa inferior à encontrada por Haddade et al. (2005), que analisaram um sistema semelhante na região Norte Fluminense e encontraram viabilidade a $10 \%$ ao ano. Essa situação é variável, pois, para cada sistema de produção explorado, consideram-se peculiaridades, índices zootécnicos diferentes, características regionais e tecnologia aplicada. Estes resultados indicam que a viabilidade da atividade leiteira está próxima ao custo de oportunidade do capital investido e que o mau gerenciamento da atividade pode levar o pecuarista a grandes perdas econômicas.

As taxas obtidas foram favoráveis à adoção de qualquer sistema de produção, pois a rentabilidade obtida foi superior à rentabilidade média da caderneta de poupança, que, durante o mesmo período de avaliação, apresentou rentabilidade média de $6 \%$ ao ano. Considerando a caderneta de poupança uma aplicação financeira de baixo risco e a principal aplicação disponível no mercado, pode-se concluir que os sistemas de produção propostos podem ser adotados pelos pecuaristas da região.

As taxas internas de retorno foram de $11,91 \%$ para a suplementação em pastagem de aveia-preta, 9,43\% para a suplementação com cana-forrageira com ureia e 8,46\% para silagem de sorgo.

O sistema de produção que utiliza a suplementação volumosa com pastagem de aveia-preta apresentou a maior TIR (11,91\%) e pode ser considerado o mais atrativo. Esse resultado incentiva os pecuaristas da região a investir na implantação de sistemas de produção que utilizam forrageiras de inverno durante a estação seca e contribuir para o aumento na quantidade de pastagens cultivadas, pois, segundo dados da APTA (2004), do total utilizado na produção bovina, 54,78\% são pastagens nativas. O aumento na utilização de pastagens cultivadas pode contribuir para melhorar os índices de desempenho produtivo por animal e por área, contribuindo para o aumento da rentabilidade da pecuária leiteira.

A taxa interna de retorno obtida (9,43\% a.a.) para o sistema que utiliza cana-forrageira como suplementação volumosa foi inferior à observada $(10,20 \%$ a.a.) por Haddade et al. (2005) em um sistema de produção de leite em pastagem com fornecimento de suplementação volumosa de cana-de-açúcar durante a estação seca.

$\mathrm{Na}$ análise de sensibilidade, os preços praticados na região durante o período de avaliação sofreram variação desfavorável de 10\% (Tabela 3) e tiveram impacto econômico negativo nos resultados obtidos para o VPL de cada sistema de produção quando esses resultados foram submetidos à taxa de desconto de 6\% ao ano. Quando o componente do sistema foi enquadrado na classe da receita, o valor do preço diminuiu e, quando o item enquadrou-se na classe das despesas, o valor do preço aumentou.
O preço de venda do leite produzido foi o item que mais influenciou nos resultados do VPL dos três sistemas de produção, seguido pelo preço de compra das matrizes leiteiras. A aquisição das matrizes leiteiras com prenhez confirmada foi considerada um investimento, pois, na elaboração e composição dos fluxos de caixa dos sistemas não foram computadas as fases de cria e recria das bezerras, ou seja, a atividade foi exclusivamente planejada para a produção leiteira. Por apresentar elevado impacto econômico na rentabilidade dos sistemas, pode-se considerar que a pecuária leiteira é uma atividade que depende do comportamento da economia mundial e das políticas públicas aplicadas, pois variações desfavoráveis nos preços de comercialização do leite e pagos aos pecuaristas podem provocar perdas significativas na atividade.

O sistema de produção que utiliza pastagem de capimmombaça e aveia-preta como suplementação volumosa apresentou como terceiro item mais sensível o preço de compra das terras para o plantio de culturas, no caso específico, a pastagem de aveia-preta. Este fato decorre da necessidade de maior área de plantio para a forrageira. Ressalta-se que, para implantar esse sistema, o pecuarista deve aumentar o uso e o potencial dessas áreas, não somente utilizando-as para o cultivo dessa forrageira, mas para outros fins de cultivo, e de forma controlada, pois, com a máxima exploração do potencial das terras, certamente a rentabilidade da atividade irá aumentar.

No sistema de produção que utiliza capim-mombaça com suplementação com cana-forrageira no cocho apresentou como o terceiro item mais sensível às variações de preços a mão-de-obra temporária, a qual envolve os custos com contratação temporária e encargos trabalhistas de funcionários por um período de 180 dias. Esses custos estão envolvidos em sua maioria no corte, na limpeza e no transporte de cana para alimentação do rebanho, além de práticas de manejo e limpeza do canavial para a próxima colheita.

O aluguel de máquinas e implementos agrícolas para o preparo do solo, o plantio, a colheita e produção de silagem foi o item que ocupou a terceira colocação na análise de sensibilidade do sistema de produção que utiliza pastagem de capim-mombaça com suplementação volumosa de silagem de sorgo, no cocho. Esse fato está relacionado aos custos envolvidos na produção dessa fonte de suplementação volumosa por se tratar de uma cultura anual de ciclo curto.

No entanto, é importante que o pecuarista, antes de escolher qual sistema de produção implantar, avalie suas condições orçamentárias, as características de sua propriedade e a possibilidade de fácil escoamento da sua 
produção e de aliar-se a outros pecuaristas vizinhos para aumento na escala de produção e da competitividade na cadeia agroindustrial do leite. A dificuldade de aquisição de terras e o alto preço de negociação podem inviabilizar a aplicação do sistema que utiliza suplementação volumosa com pastagem de aveia-preta, enquanto, no sistema com uso de suplementação volumosa com cana-forrageira, pode-se considerar que em regiões com baixa disponibilidade de mão-de-obra isso seria inviável. A dificuldade de alugar ou adquirir máquinas e implementos agrícolas pode inviabilizar o sistema com suplementação volumosa com uso da silagem de sorgo.

Países que subsidiam a produção leiteira exercem grandes impactos na atividade de países que não fornecem o subsídio, uma vez que os pecuaristas subsidiados não sofrem descapitalização quando o mercado se apresenta desfavorável, permitindo sua sustentabilidade na atividade. Quando o comportamento do preço de venda do leite produzido é desfavorável, os pecuaristas que não detêm subsídios governamentais passam por dificuldade e redução na rentabilidade da atividade, pois o leite, por ser um produto de alta perecibilidade, não pode ser estocado nas propriedades. Essa situação força os pecuaristas a entregar o produto para entrepostos de cooperativas ou indústrias lácteas que oferecem baixa remuneração. A partir deste momento, os pecuaristas iniciam um processo de descapitalização da atividade, sem identificar os sinais de inviabilidade da atividade.

Nos três sistemas de produção com suplementação volumosa, os fertilizantes merecem atenção especial, pois este item apresentou elevada sensibilidade diante da variação de preços simulada no mercado dentro dos principais itens que exercem impacto nos resultados econômicos da atividade. Esse fato é decorrente do investimento para formação e manutenção da pastagem e das fontes suplementares de volumosos.

Não foi considerado nos fluxos de caixa dos sistemas de produção propostos o uso integral das áreas utilizadas para produção de volumosos utilizados como suplementação. Além disso, a adoção de duas tecnologias exploradas na mesma área adquirida pode ainda melhorar a rentabilidade da atividade leiteira, por exemplo, produzir sorgo para silagem no período da chuva (verão) e, após a colheita e produção da silagem, promover a semeadura de aveia-preta na mesma área para formação de pastagem de inverno durante o período da seca (inverno). Outro fator a ser considerado

Tabela 3 - Resultado da análise de sensibilidade: mudança do VPL, decorrente da redução de 10\% nos preços

\begin{tabular}{|c|c|c|}
\hline Sistema & Categoria & Variação do VPL (R\$) \\
\hline \multirow[t]{10}{*}{ Pastagem de aveia-preta } & Preço de venda do leite produzido & $95.441,62$ \\
\hline & Preço de compra das matrizes leiteiras & $12.014,34$ \\
\hline & Preço de compra das terras para plantio de culturas & $5.623,80$ \\
\hline & Aluguel de máquinas e implementos agrícolas & $5.469,55$ \\
\hline & Aluguel de pastos & $5.177,95$ \\
\hline & Preço de venda das bezerras & $3.978,12$ \\
\hline & Compra de fertilizante nitrogenado - ureia & $2.897,29$ \\
\hline & Compra de fertilizante de cobertura - 20-05-20 & $2.892,34$ \\
\hline & Preço de venda das matrizes leiteiras & $2.829,45$ \\
\hline & Preço de compra das terras para pastagens & $2.807,25$ \\
\hline \multirow[t]{10}{*}{ Cana-forrageira com ureia } & Preço de venda do leite produzido & $82.010,56$ \\
\hline & Preço de compra das matrizes leiteiras & $12.014,33$ \\
\hline & Mão-de-obra temporária & $5.204,70$ \\
\hline & Aluguel de pastos & $5.177,95$ \\
\hline & Preço de venda das bezerras & $3.978,12$ \\
\hline & Compra de fertilizante de cobertura - 20-05-20 & $3.160,61$ \\
\hline & Preço de venda das matrizes leiteiras & $2.829,46$ \\
\hline & Preço de compra das terras para pastagens & $2.807,24$ \\
\hline & Consultoria técnica & $2.489,96$ \\
\hline & Compra de fertilizante nitrogenado - ureia & $1.749,73$ \\
\hline \multirow[t]{10}{*}{ Silagem de sorgo } & Preço de venda do leite produzido & $88.182,59$ \\
\hline & Preço de compra das matrizes leiteiras & $12.014,33$ \\
\hline & Aluguel de máquinas e implementos agrícolas & $6.103,00$ \\
\hline & Compra de lona plástica para fechamento do silo & $5.912,00$ \\
\hline & Aluguel de pastos & $5.177,95$ \\
\hline & Preço de venda das bezerras & $3.978,12$ \\
\hline & Compra de fertilizante de cobertura - 20-05-20 & $3.496,60$ \\
\hline & Preço de venda das matrizes & $2.829,45$ \\
\hline & Preço de compra das terras para pastagens & $2.807,24$ \\
\hline & Consultoria técnica & $2.489,96$ \\
\hline
\end{tabular}


é que a combinação desses dois sistemas maximizando a exploração das terras reduz o uso de corretivos e fertilizantes na implantação de cada um individualmente, tendo em vista seu efeito residual, beneficiando a cultura seguinte.

A alimentação com uso de concentrados tem grande influência na pecuária leiteira. Entretanto, não foi classificada entre os itens mais sensíveis, pois houve baixo nível de fornecimento, diariamente. Essa situação experimental foi realizada utilizando animais do biotipo Mantiqueira, que apresentam características de alta rusticidade e adapta-bilidade às condições climáticas da região. Em situação semelhante de exploração em que se utilizam animais mais especializados para a produção leiteira, o arraçoamento com uso de concentrados na quantidade utilizada neste trabalho é insuficiente para atender às necessidades nutricionais diárias desses animais, considerados exigentes e mais produtivos.

Os principais itens de maior impacto nos resultados econômicos dos três sistemas de produção coincidem com os resultados publicados por Haddade et al. (2005), que observaram que os preços de venda do leite produzido, de compra e venda de matrizes leiteiras são os principais itens que podem inviabilizar o sistema proposto para a região Norte Fluminense em caso de grandes oscilações nos preços.

\section{Conclusões}

Os sistemas de produção de leite em pastagem de capim-mombaça com uso de suplementação volumosa durante a estação seca são viáveis financeiramente quando submetidos à taxa de desconto de $8 \%$ ao ano. O sistema de produção em pastagem de capim-mombaça suplementada com aveia-preta durante a estação seca apresenta o maior valor presente líquido e taxa interna de retorno mais atrativa. O preço de venda do leite produzido é o item de maior impacto nos resultados econômicos dos sistemas de produção avaliados.

\section{Agradecimentos}

Ao pesquisador Irineu Arcaro Júnior, que, como representante do Departamento de Descentralização do Desenvolvimento da APTA, viabilizou a implantação dos sistemas de produção testados.

\section{Literatura Citada}

AGÊNCIA PAULISTA DE TECNOLOGIA DOS AGRONEGÓCIOS APTA. Anuário IEA 2003 - Série informações estatísticas da agricultura. 1.ed. São Paulo: APTA, 2004. 320p.

BUARQUE, C. A incerteza para seleção de projetos. In: BUARQUE, C. (Ed.) Avaliação econômica de projetos. 8.ed. Rio de Janeiro: Editora Campus, 1991. p.179-196.

CONTADOR, C.R. Indicadores para seleção de projetos. In: CONTADOR, C. (Ed.) Avaliação social de projetos. 2.ed. São Paulo: Editora Atlas, 1988. p.41-58.

FUNDAÇÃO GETÚLIO VARGAS - FGV. [2006]. Índice geral de preços - disponibilidade interna - IGP-DI. Disponível em: <http://www.fgvdados.com.br>. Acesso em: 12/9/2006.

HADDADE, I.R.; SOUZA, P.M.; BARROS, E.E.L. et al. Avaliação econômica sob condições de risco em sistema produtivo de gado de leite na região Norte do estado do Rio de Janeiro. Arquivo Brasileiro de Medicina Veterinária e Zootecnia v.57, n.3, p.361-366, 2005.

JANK, M.S.; FARINA, E.M.Q.; GALAN, V.B. O Agribusiness do leite no Brasil. 1.ed. São Paulo: Editora Milkbizz, 1999 108 p.

KRUG, E.E.B. Produção de leite: problemas e soluções. In: KOCHHANN, R.A.; TOMM, G.O.; FONTANELI, R.S. (Eds.) Sistemas de produção de leite baseado em pastagens sob plantio direto. 1.ed. Passo Fundo: Centro Nacional de Pesquisa em Trigo, 2000. p.09-55.

MELO, A.C.G.; REIS, M.S.; GOSRTIN, B.G. Análise financeira de projetos de investimento sob enforque de incertezas. In: SEMINÁRIO NACIONAL DE PRODUÇÃO E TRANSMISSÃO DE ENERGia ElétriCA, 1., 1999, Foz do Iguaçu. Anais... Paraná, 1999. p.1-6.

MINISTÉRIO DA AGRICULTURA, PECUÁRIA E ABASTECIMENTO - MAPA. [2002]. Instrução Normativa N.51. Disponível em: <http://www.agricultura.gov.br>. Acesso em: 18/12/2006.

NORONHA, J.F. Projetos agropecuários: administração financeira, orçamento e viabilidade econômica. 2.ed. São Paulo: Editora Atlas, 1987. 269p. 